\title{
Paramedian thalamic and midbrain infarcts associated with palilalia
}

\author{
Yuzuru Yasuda, Ichiro Akiguchi, Masashi Ino, Hidehiko Nabatabe, Masakuni Kameyama
}

\begin{abstract}
A patient with paramedian thalamic and midbrain infarcts developed palilalia.
\end{abstract}

Palilalia is a speech abnormality characterised by compulsive repetition of a phrase or word and was first described by Souques in $1908 .^{1}$ Reports of palilalia are rare and the cause is unknown. Clinical and neuropathological findings by Boller et $a l^{2}$ concluded that it is associated with a disturbance of the extrapyramidal system.

Patients with paramedian thalamic lesions show altered consciousness, ocular motility changes, abnormal movements, memory disturbance, and aphasia. ${ }^{3-8}$ We observed a patient with palilalia for four months. MRI showed infarcts in the medial thalami, subthalami and midbrain on both sides, but no other lesions. We present the first report of paramedian thalamic and midbrain infarcts associated with palilalia.

Department of

Neurology, Kyoto City

Hospital

Y Yasuda

Department of

Neurology, Faculty of

Medicine, Kyoto

University

I Akiguchi

M Ino

H Nabatabe

Department of

Neurology, Sumitomo

Hospital, Japan

M Kameyama

Correspondence to:

Dr Y Yasuda, Department of

Neurology, Kyoto City

Hospital, Higashi-

Nakagyoku, Kyoto 604,

Japan.

Received 7 July 1989 and in revised form 25 September 1989.

Accepted 11 October 1989

\section{Case report}

A 62 year old man fell while walking in the garden on 5 June 1986. Paraesthesia developed from the left cheek to the left corner of his mouth and he became blind in the left eye. He did not complain of vertigo, nausea or vomiting and was admitted to hospital as an emergency. On admission he was comatose and showed flaccid tetraplegia. He had dilatated non-reactive pupils. Doll's head movements were absent. Two days later, he began to improve gradually. Neurological examination revealed bilateral cerebellar ataxia, oculomotor nerve palsy, lack of spontaneity, and amnesia. Deep tendon reflexes, power and sensation were normal. Babinski sign was noted on the right side. Muscle tone was decreased. Ten days later, he began to say his name and speak simple words. Two months later, he began to show compulsive repetition of syllables, words, or phrases, and was transferred to our hospital.

On admission, physical examination was normal except for the pulse rate which was 46 / min. Neurologically he was apathetic, and continued to lie in bed if other instructions were not given. He could however understand questions and eat food in a sitting position with help. His pupils were dilated on both sides (right $8 \mathrm{~mm}$, left $6 \mathrm{~mm}$ ), and light reaction was absent. Bilateral ptosis was seen, and his eyes were divergent. Eye movement was restricted in all directions, except for a slight medial gaze. Convergence was absent. Doll's head and Bell's phenomena were not seen. Other cranial nerves were normal. Although deep tendon reflex was normal, Babinski sign was elicited on the right side. Though muscle strength was normal in the extremities, muscle tone was decreased. Finger-to-nose test and heel-to-knee test were clumsy and marked hypermetria was observed. He showed marked ataxic gait, but could walk a short distance unaided.

When his speech was not repetitious it was slow and indistinct. When he became repetitious, the rate of speech gradually increased, the loudness reduced, and finally he began to whisper. A syllable or word was involuntarily repeated five to ten times in spontaneous speech or in reply to a question; repetition of phrases being more infrequent than that of syllables or words. This patient's palilalia was rarely noticed when he repeated words spoken to him by the examiner. Slight perseveration was seen. Literal and verbal paraphasia was not present. When asked, for example, how his condition was, his answer was "guai-guaiguai-guai-guai ima-ima-ima-ima toku-tokutoku-tokuni ii-desu"' (guai = condition, ima = now, tokuni $=$ especially, $\mathrm{ii}=$ good, desu = a particle).

Despite marked ataxia and photophobia, his writing was preserved. Right left disorientation, apraxia and agnosia were absent. Wechsler Adult Intelligence Scale verbal IQ was 83 , but a performance test could not be carried out because of his ataxia. Recent verbal and visual memories were moderately disturbed, and immediate ones only slightly.

Laboratory findings including complete blood count and serum calcium, blood urea nitrogen, creatinine phosphokinase, alkaline phosphatase, and glutamic oxalacetic transaminase were normal. Electrocardiogram showed sinus bradycardia.

The basic rhythm on EEG was $7 \mathrm{~Hz}$ theta and $8-9 \mathrm{~Hz}$ alpha waves, and sporadic $4-5 \mathrm{~Hz}$ theta waves were seen bilaterally. A vertebral angiography showed no stenosis of basilar artery, thalamogeniculate artery, posterior choroidal artery, and thalamoperforating 
Figure MRI. A.B: Partial saturation $(T R=$ $400 \mathrm{~ms}, T E=25 \mathrm{~ms}$ ), C.D: Spin echo (TR $2500 \mathrm{~ms}, T E=80 \mathrm{~ms}$ ). Bilateral infarcts in the medial thalami,

subthalami, and midbrain.
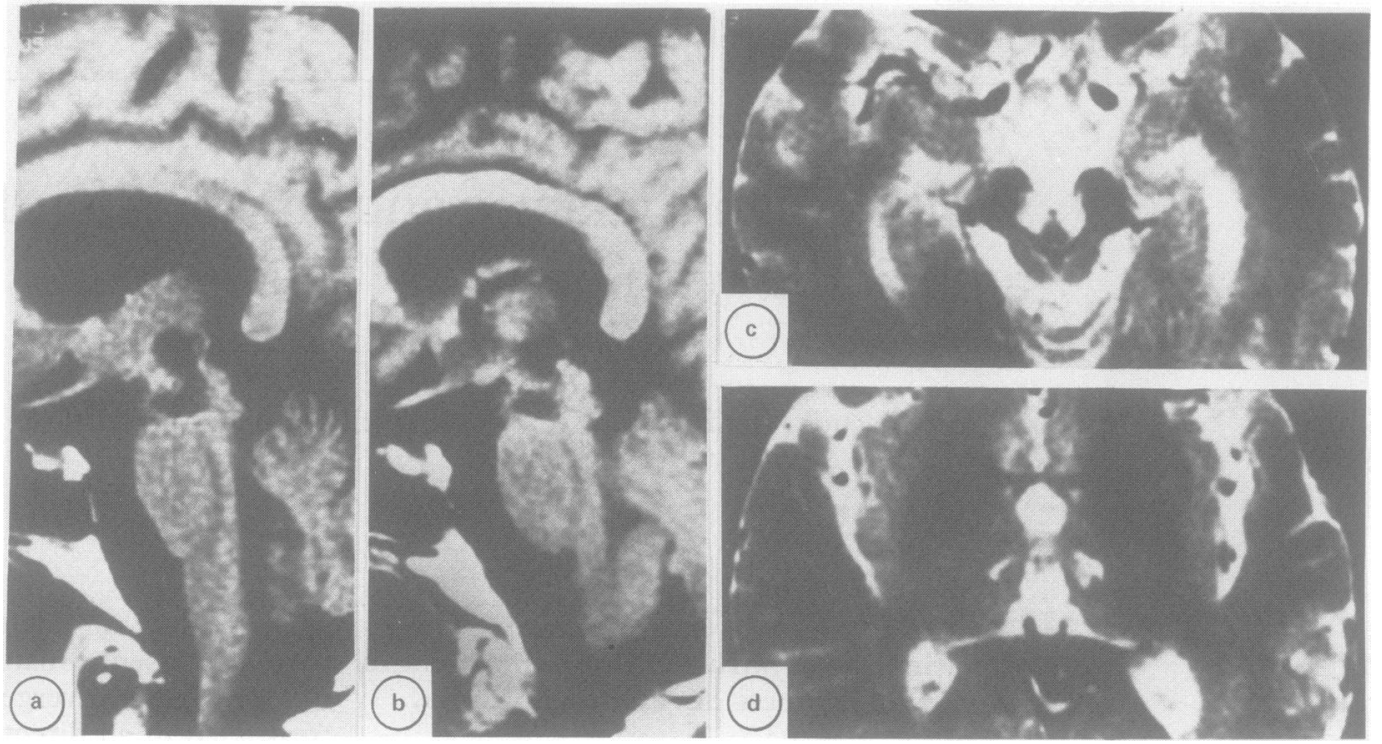

artery. MRI showed infarcts in the medial thalami, subthalami and midbrain on both sides (fig), but no other lesions. Somatosensory evoked potentials (SEP) showed no abnormality. Brainstem evoked response showed delayed latency of $\mathrm{V}$-waves on both sides $(6.4 \mathrm{~ms})$ and $\mathrm{I}-\mathrm{V}$ time was prolonged $(4.7 \mathrm{~ms})$, which showed a disturbance of the midbrain.

The palilalia gradually disappeared and was almost imperceptible by December 1986. However, the patient's speech remained slow and unsteady. Cerebellar ataxia was slightly improved, but there was no improvement in oculomotor palsy, ptosis, and mydriasis.

\section{Discussion}

Palilalia has been described ${ }^{1}$ as a speech disorder characterised by compulsive repetition of a phrase or word. Marie and Lévy ${ }^{9}$ described the characteristics as: (1) compulsive repetition of several short phrases or words on more than two occasions; (2) monotonous speech and a tendency to shorten phrases; (3) initial explosive speech with the speed gradually increasing but becoming quieter. Reports of palilalia are rare although several exist in the literature; a case with apoplexy by Souques, ${ }^{1}$ one with pseudobulbar palsy by Dupré and Savoureaux, ${ }^{10}$ one with Parkinsonism by Marie and Lévy, ${ }^{11}$ one with Parkinson's disease by Pick, ${ }^{12}$ one with Alzheimer's disease by Frey, ${ }^{13}$ and one with falx meningioma by Alajouanine. ${ }^{14}$ The common characteristics in these reports is that palilalia was often seen in spontaneous speech but rarely seen in repetition and reading.

Palilalia must be differentiated from stammering, logoclonia, and echolalia. Stammering is characterised by difficulty in producing the next expected sound; logoclonia by repetition of the last syllable of the words, and echolalia is the automatic repetition of the words addressed to the patient. In this case repetition of syllables, words, and phrases were noted and repetition was mostly observed in spontaneous speech and rarely when the patient repeated the words spoken to him by the examiner. The repetition was not restricted to the first or last syllable, and can therefore be differentiated from stammering or logoclonia. As the patient spoke, the rate of speech gradually increased, the loudness reduced, and finally he began to whisper. This phenomenon is called "palilalie aphone", which was first described by Marie and Lévy in 1922. ${ }^{11}$

Patients with paramedian thalamic lesions severation, ${ }^{4578}$ confusion, ${ }^{6}$ confabulation, ${ }^{6}$ and a tendency to echolalia. ${ }^{7}$ This reduced voice volume ${ }^{4}$ is similar to palilalie aphone, ${ }^{11}$ but compulsive repetition of phrases or words has not been reported in patients with paramedian thalamic lesions. Therefore previously reported abnormalities of speech and language with paramedian thalamic lesions ${ }^{4-8}$ differ from palilalia.

The mechanism of palilalia is thought to be tion of pronunciation by extrapyramidal dysfunction, which is based on the findings that the basal ganglia were often involved in cases with palilalia at necropsy. For example, several infarcts were seen bilaterally in the putamen, the caudate and the subthalamic nucleus in one of Pick's cases. ${ }^{12}$ Another of Pick's cases showed widespread loss of cells in the caudate and lenticular nuclei. ${ }^{12}$ Critchley's case showed small lacunae in the basal ganglia and pons. ${ }^{15} \mathrm{~A}$ case described by Contamin et al showed bilateral atrophy of globus pallidus, subthalamic nucleus and substantia nigra. ${ }^{16}$ Boller et al observed that palilalia fluctuated with chorea in familial cases that showed extensive intracranial calcifications involving the basal ganglia on both sides, and proposed that palilalia is caused by bilateral lesion in inhibitory motor circuits. ${ }^{2}$ Thus most cases with palilalia have bilateral lesions of the basal ganglia. However, cases with cerebral hemisphere on both sides, ${ }^{12}$ or one with one cerebellar hemisphere and several areas of the corpus callosum ${ }^{10}$ have been reported.

MRI showed infarcts in the medial thalami, subthalami, and midbrain on both sides, but no show reduced voice volume, ${ }^{4}$ dysarthria, ${ }^{5}$ perderived from the disturbance of accommoda- 
lesions in the basal ganglia, cerebral hemispheres or cerebellar hemispheres in this case. The dentato-rubro-thalamic tracts were involved on both sides. Within the thalamus, not only intralaminar-parafascicular-centromedian nuclei but also postero-medial nuclei may be partially involved. From the literature and our case we propose that a specific localised lesion is not necessary for the development of palilalia. Disturbance of nuclei in the subthalami, basal ganglia and thalami, and their projection areas namely widespread extrapyramidal dysfunction, may cause palilalia.

1 Souques MA. Palilalie. Rev Neurol (Paris) 1908;16:340-9. Boller F, Boller M, Denes G, et al. Familial palilalia. Neurology 1973;23:1117-25.

3 Castaigne P, Lhermitte F, Buge A, et al. Paramedian thalamic and midbrain infarcts: Clinical and neuropathological study. Ann Neurol 1981;10:127-48.

4 Stuss DT, Guberman A, Nelson R, et al. The neuropsychology of paramedian thalamic infarction. Brain and Cognition 1988;8:348-78.

5 Graff-Radford NR, Eslinger PI, Damasio AR, et al. Nonhemorrhagic infarction of the thalamus: Behavioral, anatomic, and physiologic correlates. Neurology 1984;34: 14-23.

6 Bogousslavsky J, Regli F, Uske A. Thalamic infarcts. Clinical syndrome, etiology, and prognosis. Neurology 1988;38:837-48.

7 Fensore C, Lazzarino LG, Nappo A, et al. Language and memory disturbances from mesencephalothalmic infarcts. A clinical and computed tomography study. Eur Neurol 1988;28:51-6.

8 Crosson B. Role of the dominant thalamus in language: a review. Psychol Bull 1984;96:491-517.

9 Marie P, Lévy G. Un singulier trouble de la parole: la palilalie. Monde Méd 1925;35:329-44.

10 Dupré E, Savoureaux L. Palilalie chez une pseudo-bulbaire. Rev Neurol (Paris) 1914;27:453-6.

11 Marie P, Lévy G. Palilalie et syndrome parkinsonien par encéphalite épidémique. Rev Neurol (Paris) 1922;29: 6-80.

12 Pick A. Die Palilalie, ein Teilstück striärer Motolitätsstörungen. Abhandl Neurol Psychiatr Psychol 1921;13:178-224.

13 Frey E. Beiträge zur Klinik und pathlogischen Anatomie der Alzheimerschen Krankheit. Z Gesamte Neurol Psychiatr 1914;27:397-434

14 Alajouanine Th, Castaigne $P$, Sabouraud $O$, et al. Palilalie paroxystique et vocalisations itératives au cours de crises épileptiques par lésion intéressant l'aire motorice supplémentaire. Rev Neurol (Paris) 1959;101:685-97.

15 Critchley M. On palilalia. J Neurol Psychopathol 1927;8: 3-32.

16 Contamin F, Escourolle R, Nick J, et al Atrophic pallidonigro-luysienne. Syndrome akinétique avec palilalie,
rigidité oppositionelle et catatonie. Rev Neurol (Paris) 1971;24:107-20. 